\title{
Rice Paddy to Kung Fool Mask: Race and Cultural Awareness in International and Transracial Adoption Communities
}

\author{
Linh Thuy Song ${ }^{1}$
}

\begin{abstract}
Mam Non, an innovative facilitated self-help organization for Vietnamese adults adopted and brought to North America as children and for families engaged in transracial adoption of Vietnamese and S.E. Asian children, serves as an illustration of how culturally competent family practice can be carried out in a large group setting benefiting all group members. Illustrations of the public and private tensions related to transracial adoption are outlined, as is the role of the reflective family practitioner in helping all participants to place their actions in historical, social, and political contexts.
\end{abstract}

Key Words: Transracial adoption, Vietnamese children, Southeast Asian adoptions, self-help family groups, multiple family groups, facilitated family groups, culturally competent practice

${ }^{1}$ Linh Thuy Song, MSW is Director of the Mam Non Organization, Vietnam. Electronic mail may be sent via the Internet to linh.song@gmail.com.

The transracial and adoption communities have looked to culture or heritage camps for the past 20 to 30 years as a way to celebrate their children's heritages and, more recently, to explore the complexities behind a multicultural family. Generally organized by adoption agencies and white adoptive parents, the camps suit the adoption community's demand for venues that normalize their family makeup while also seeing to their educational and cultural needs. Although organizers have often partnered with communities of color and, if possible, community members who share their children's heritages, the camps have been known to make some unfortunate mistakes. In one case, a Vietnamese culture camp recreated a Vietnamese rice paddy for the children to plant rice and find plastic fish. While there were other programs on Vietnamese urban life, crafts, and adoption workshops, this one activity raised questions of how the adoption community should promote positive ethnic and racial identities. How could an activity that mimicked third-world labor benefit adoptees? What can the community do to avoid 
essentializing and exoticizing cultures? What are the resources available to the adoption community besides media images and books? What kind of cultural competency should we expect from adoptive parents and camp organizers?

These questions ignited the primary electronic listserv for the Vietnamese adoption community. Some of the over 40 families who had attended the camp were members of the 2,500-member Adoptive Parents of Vietnam (APV), and many took the opportunity to express their confusion, dismay, and support over the camp activity. One member fondly recollected how her son enjoyed playing in the rice paddy with other preschoolers. Another mother insisted that rice farming is a real profession in Vietnam and that it could have been their children's reality if they had not been adopted. Yet another parent wrote that she was uncomfortable but couldn't put her finger on what exactly irked her.

At the time, I was a vocal member of the list because of my personal and professional affiliations with the adoption community. I am a second-generation Vietnamese American with adopted family members spanning three generations. I am also the founder and director of the Mam Non Organization, a group that focuses on racial and cultural awareness within the adoption community. The impetus behind the organization's goals grew from my own experiences as a minority woman, as an organizer within the greater Vietnamese American community, and from my ambition of bringing both Vietnamese American and adoption communities together to cultivate positive ethnic, racial, and cultural identities for all Vietnamese children. The overall objective for my organization is to empower families so that they can ably meet the challenges of international and transracial adoption and not be intimidated by its complexities. Moreover, we aim to develop critical awareness so that they can be advocates for their families and informed members of the greater community of color. With that in mind, along with Mam Non participants, I realized that there was a great need for cultural information and exposure so that Vietnamese identities could be cherished and informed. It was because of these experiences that I took great issue with the camp's choice.

The analogy that I offered was that we would most likely balk at a culture camp's recreation of a cotton plantation for African American children. The imagery alone harbors sentiments of oppression, poverty, and forced labor. It is also quite racialized and connected to an unromantic history that should not be trivialized. The rice paddy, while seemingly innocuous, revealed not only the organizers' and parents' ignorance of Vietnamese culture and history but also of race and economic dynamics. Having young Vietnamese children in a rice paddy, supervised by white parents, was too close to our colonial history. Vietnamese slaves had worked on rubber tree plantations for French overseers during the $19^{\text {th }}$ century (Tran, Marr, \& Ha, 1985). Also, rice farming in modern Vietnam is not a profession of choice given poverty and economic limitations. I argued that Vietnamese American families do not build rice paddies to teach their children what it means to be Vietnamese. Surely, this community would be better able to guide adoptive 
families in their quest to preserve their children's heritages from exposure to same-race communities, as researchers have shown (e.g., Park \& Green, 2000; Hollingsworth, 1998; National Association of Black Social Workers, 1994). In the future, when children from both groups recognize each other as peers, what will the consequences be when adoptees realize that their friends did not indulge in similar activities? Finally, there seemed to be a danger in how adoption communities construct, interpret, and preserve their children's birth culture - especially when they perpetuate stereotypes of Vietnamese coolies.

The culture camp listserv discussion eventually touched on issues of race, oppression, authenticity, and relationships between the adoption and greater Vietnamese and Asian American communities. The e-mail list is quite diverse with members at all points of adoption: "paperchasing" or preadoption, postadoption, adult adoptees, new parents, parents with multiple international adoptions, and parents with adult adoptee children. Fortunately this diversity allowed for multiple interpretations, frank observations, and examples that took cultural competency out of academic and politically correct jargon into real life scenarios. One member privately - and wryly - remarked, "Is having a rice paddy in the best interests of my child?"

As a practitioner, I felt that this controversy was an interesting play on what researchers and adoption workers have considered important in terms of placement and adjustment of transracially adopted children. Studies have more often focused on children's racial self-awareness (McRoy, 1983) and adjustment (Simon \& Altstein, 1987: 1992; Westhues \& Cohen, 1994: 1997; Levy-Shiff, Zoran, \& Shulman, 1997) than on how adoptive parents promote and cultivate their children's racial and cultural identities. Since we know that adoptive parents' attitudes, expectations, and value systems influence their children's sense of self (Bornstein, 1995; Huh \& Reid, 2000), developing cultural competence seems critical. Vonk (in press) defines cultural competence for transracial adoptive parents as "the transformation of a particular set of attitudes, knowledge, and skills in the ability to meet children's unique racial and cultural needs." She describes a three-step process of racial awareness, survival skills, and multicultural planning to meet these needs. I would also add a step where adoptive parents can critically evaluate cultural information, their interpretations of this information, and expand their choice of resources.

Unfortunately there is a gap between research and practice where families are left wanting to continue their children's connection with his or her birth culture but have few ways of doing so. As a result, these children have had minimal contact with other members of their race (Haugaard, Dorman, \& Schustack, 1997), and children placed transracially (Simon \& Altstein, 1987; McRoy, 1994; McRoy \& Zurcher, 1983) do not have as strong of a sense of ethnic or racial identity as those placed with families of a similar ethnic or racial background.

While some agencies and adoption specialists have made progress by turning away from promoting color blindness, an overly simplistic approach wherein families 
minimize their children's differences, more needs to be done to promote interaction with same-race and same-ethnic communities. In my work with Vietnamese adoptive families, I am often struck by their reliance on reading materials and mass media for their connection to Vietnamese culture and to some extent, Asian American culture and history. Research has shown that this is not an isolated phenomenon. In one study, while 70 percent of the children sampled were periodically exposed to their birth culture, this connection was accomplished primarily through reading materials in 90 percent of families. Half the children seldom had contact with people of their own culture, and 10 percent of parents reported that it never occurred. This result supports other findings indicating that most internationally adopted children have limited contact with same race community members (Haugaard et al., 1997).

One example of such cultural exposure is a Vietnamese adoptee's experience. He had spoken on one of Mam Non's adult adoptee panels and poignantly remarked how his exposure to Vietnamese and Asian Americans was limited to the people who literally served his family at the local Chinese restaurant. Later, he struggled with sifting through the information his parents provided and what he needed to learn in order to establish relationships with the Vietnamese and Asian American community. An example he gave was how his parents used Vietnam War publications geared towards military personnel, mistakenly teaching him how to say "I love you" in the informal form used from man to woman that is not meant for communication between other family members. Another Korean adult adoptee still remembers that, as a child, he thought that all Koreans could sing and dance very well because of the one children's book that his parents read to him. That was his primary concept of what it meant to be Korean.

There remains a great deal of confusion when it comes to cultivating critical and accurate conceptualizations of race, ethnicity, culture - and even history-within the transracial and international adoption community. For example, I had spoken at another Vietnamese culture camp on Vietnamese American politics and sentiments of the Vietnam War era. Afterwards, one adoptive mother confided that she was unaware that the United States had lost the war. Though the mother had traveled to Vietnam on several occasions to complete her adoptions and had completed preadoption counseling and cultural competence training, she did not seem to be aware of a dominating theme in the Vietnamese diaspora. Later, when I mentioned this to another adoptive mother, she remarked that she often forgets that her children are Vietnamese and that it is only at these camps that she reminds herself and tries to catch up. This viewpoint of not considering her children racially coincides with research on transracial adoptive families seeing their children differently at home than in public. It is in public that their perceptions are racialized since their family makeup is atypical, and they are forced to feel more conscious of it (Westhues \& Cohen, 1998).

These were remarkable experiences. As a practitioner and Vietnamese American who hopes to realize a more informed and ethnoracial conscious adoption community, I 
realized that these families cannot be expected to forge their paths alone. I look to family practitioners and adoption agencies to reassess pre- and postadoption services to the international and transracial adoption communities. In a sample of 192 public and private adoption agencies, slightly over half provided cultural competence training (Vonk \& Angaran, 2003). Most, but not all, of the agencies required such training of transracially adoptive parents. These results suggest a need for services to those who do not receive the necessary training and preparation for challenges related to race and culture. The study also pointed to frequent agency failings with respect to timing. The majority of cultural competence services were provided before placing the child, but more needs to be done post-placement. Prior to placement these issues can be abstract and not as much of a priority as later, when the children grow older and their real-life experiences enter the equation (Kallgren \& Caudill, 1993).

Fortunately, the international and transracial adoption communities have expanded their resource base by organizing themselves according to sending countries, travel groups, their children's provinces, locale in the United States, and-most remarkably, online. While agencies and other adoption practitioners scramble to meet postplacement needs, families have organized massive online communities where email conversations cover everything from unethical adoption facilitators and traffickers to orphanage conditions and racism. For example, the Adoptive Parents of China (APC) email list has over 25,000 worldwide members and remains a dominating resource for families seeking cultural and adoption process information. Also, the International Adopt Talk (IAT) listserv has proven to be an invaluable resource as adult adoptee moderators and members freely exchange their experiences with adoptive parents.

Discussion on the APV listserv has remained active as the children become older and more complex challenges arise. As the new list moderator, I have encouraged open discussions. An often repeated discussion is on stereotypes and slurs to watch for when the children start elementary school. Interestingly enough, although listings of slurs are requested, discussions will often delve into how much more there is to be mindful of besides slurs, such as subtle peer and teacher interactions. What the listserv provides is a sense of anonymity and supportive community where parents are not reprimanded by an agency social worker for using the word Oriental (a common experience on the list) and never learning why it is inappropriate. It has also proved to be a suitable venue for racial awareness exercises and for empowering the international and transracial adoption communities into social justice actions.

In 2002, two years after the rice paddy activity (the camp never attempted it again), a Halloween mask depicting a bruised, bucktoothed, and slanty-eyed Asian man was made available at national retail stores. The mask was called "Kung Fool," capturing popular stereotypes and enraging the Asian American community. All but one Michigan based retailer had removed the mask from store shelves. Mam Non spearheaded a protest which led to its removal. We had purposefully looked to the adoption and greater Asian and Vietnamese American communities for assistance and as a way to build allies, a step 
towards building relations and understanding between communities. In the process, one adoptive mother on the APV listserv wondered if perhaps she was being too sensitive in her angry reaction - that perhaps this was a harmless mask. This sentiment was very similar to that of some other members who had remarked that the culture camp rice paddy was harmless fun. Later, as the protest grew, she wrote about how she had realized that the issue at hand was not so much her own reaction but that of her child's. She had learned to recognize racism and understood how harmful it could be to her child's selfconfidence.

A Chinese American friend who also participated in the protest shared almost the exact same sentiment. He feared that his daughter would see children at school wearing the mask and hoped that she would know that it wasn't a reflection of her or her race. While he looked to racial minority coping skills from his own and his family's experiences, the adoptive mother looked to what she had learned from online conversations and recollection of adoption agency material. But what brought everything together was the sense that something could be done to change racist situations and not just cope with them. This experience of empowerment and advocacy on her child's behalf is a good example of how adoption and communities of color can look to each other when challenged.

As powerful as online adoption communities might be, the caveat is that this resource is self-selective and perhaps not so removed from reading material that the community relies on for cultural and racial information. Mam Non has been able to offer opportunities for adoptive families to develop peer relationships with Vietnamese Americans and not just e-mail conversations or the usual contact at Vietnamese restaurants and nail salons. We also have extended our programs (e.g., cultural celebrations, Asian American Heritage Month Picnic) to the greater Asian American and Asian adoptee communities so that there is a mutual understanding of cultural maintenance and racial awareness.

One effective activity is an introductory bingo where event attendees are asked to find people with certain backgrounds in order to win a prize. Members of multiple communities are forced to meet each other and are often surprised to learn that a Vietnamese American father works at the same company, that an adoptive family lives in the same neighborhood or city, or that a Korean American volunteer skateboards. All the while, the Vietnamese and Asian American communities can learn about the mechanisms of transracial adoption (why and how), confront their own ambivalence towards nonfamilial adoption, and explore the idea that communities can be build upon mutual hopes for their families to build positive and informed ethnic and racial identities (Carstens \& Julia, 2000).

\section{Conclusion}

I have already seen a shift by adoptive parents, moving their attention from 
learning about Vietnam to learning about Vietnamese Americans, people who are their own and their children's peers. Although the process is certainly more challenging than relying on websites, books, and recipes, the rewards have resulted in lifetime friendships and practical insights. These community experiences could potentially prevent future cultural essentialism and promote partnerships while advancing positive cultural and racial pride with Vietnamese American children.

While the experiences I have described demonstrate the successes and advantages of connecting a transracial adoptive community with a community of color, the onus is on social workers and family professionals as well as adoption agencies to adequately prepare adoptive families on an ongoing basis. Preadoption programs that skim over how race works and why it is still an issue perpetuate the disbelief and ignorance that some families might already work from. It should be emphasized that developing cultural competency is a tool towards understanding and normalizing the adoption experience (Vonk \& Angaran, 2001). Once that is established, then perhaps explorations on race, ethnicity, and culture can begin in an informative, if not challenging, manner with the assistance of ethnoracial community members, organizations, and adult adoptees.

\section{References}

Bornstein, M. H. (Ed.) (1995). Handbook of parenting, Vol. 1: Children and parenting. Hove, UK: Erlbaum.

Carstens, C., \& Julia, M. (2000). Ethnoracial awareness in intercountry adoption: U.S. experiences. International Social Work, 43, 61-73.

Haugaard, J. J., Dorman, K., \& Schustack, A. (1997). Research digest: Transracial adoptions. Adoption Quarterly, 1 (2), 87-94.

Hollingsworth, L. D. (1998). Adoptee dissimilarity from the adoptive family: Clinical practice and research implications. Child and Adolescent Social Work Journal, 15, 303-319.

Huh, N. S., \& Reid, W. J. (2000). Intercountry, transracial adoption and ethnic identity: A Korean example. International Social Work, 43, 75-87.

Kallgren, C. A., \& Caudill, P. J. (1993). Current transracial adoption practices: Racial dissonance or racial awareness? Psychological Reports, 72, 551-558.

Levy-Shiff, R., Zoran, N., \& Shulman, S. (1997). International and domestic adoption: Child, parents, and family adjustment. International Journal of Behavioral Development, 20, 109129.

McRoy, R. G. (1994). Attachment and racial identity issues: Implications for child placement decision making. Journal of Multicultural Social Work, 3, 59-74. 
McRoy R., \& Zurcher, L. A. (1983). Transracial and inracial adoptees: The adolescent years. Springfield, IL: Charles C. Thomas.

National Association of Black Social Workers (1994). Preserving African-American families (Position statement). Washington, DC: NABSW.

Park, S. M., \& Green, C. E. (2000). Is transracial adoption in the best interest of ethnic minority children?: Questions concerning legal and scientific interpretations of a child's best interests. Adoption Quarterly, 3 (4), 5-34.

Simon, R.J. \& Altstein, H. (1987). Transracial adoptees and their families: A study of identity and commitment. New York: Praeger.

Simon, R. J. \& Altstein, H. (1992). Adoption, race, and identity: From infancy through adolescence. New York: Praeger.

Tran, T. B., Marr, D. G., \& Ha, A. (1985). The red earth: A Vietnamese memoir of life on a colonial rubber plantation, Vol. 66, Monographs in International Studies, Southeast Asia Series. Athens, OH: Ohio University Center for International Studies and Center for Southeast Asian Studies.

Westhues, A., \& Cohen, J. S. (1994). Intercountry adoption in Canada. Ottawa, ON: National Welfare Grants, Human Resources Development Canada.

Westhues, A., \& Cohen, J. S. (1997). A comparison of the adjustment of adolescent and young adult intercountry adoptees and their siblings. International Journal of Behavioural Development. 20 (1), 47-65.

Westhues, A., \& Cohen, J. S. (1998). Ethnic and racial identity of internationally adopted adolescents and young adults: A discussion in relation to children's rights. Adoption Quarterly, 1 (4), 33-55.

Vonk, M. E., \& Angaran, R. (2003). training for transracial adoptive parents by public and private adoption agencies. Adoption Quarterly, 6, 53-62.

Vonk, M. E. (in press). Cultural competence for transracial adoptive parents. Social Work. 